\title{
Entegre Entropi ve EATWOS Yöntemleri Kullanılarak Karadeniz Konteyner Limanlarının Verimlilik Analizi
}

\author{
Ömer Faruk Görçün ${ }^{1}$
}

Entegre Entropi ve Eatwos Yöntemleri Kullanılarak Karadeniz Konteyner Limanlarının Verimlilik Analizi

Öz

Karadeniz Bölgesi küresel ticaret için son derece önemli bir bölgedir. Kısa mesafe deniz taşımacılığı ile deniz otobanları yaklaşımlarının Avrupa Birliğinin gündeminde olması Karadeniz limanlarının önemini her geçen gün artırmaktadır. Dolayısıyla Karadeniz limanlarının performansları yakın gelecekte gösterecekleri gelişme ve ilerlemelere büyük ölçüde etki edebilecek faktörler olabilecektir. Limanların etkinlik ve verimlilikleri çok sayıda değişken ve faktör tarafından etkilendiği için sistematik ve yapısal bir çerçeve olarak kullanılabilecek çok kriterli karar verme yöntemlerinin kullanılması gerekmektedir. Bu çalışmada entropi ve EATWOS yöntemleri entegre edilerek oluşturulan bir hibrid model Karadeniz limanlarının etkinlik ve verimlilik analizi için kullanılması önerilmektedir. Bu yöntem sayesinde elde edilecek çıktıların lojistik süreçlerde yer alan aktörlerin dışında yatırımcılar ve kamu otoriteleri tarafından da kullanılabilir bir nitelik taşıyacağı öngörülmektedir.

Anahtar Kelimeler: Entropi Yöntemi, EATWOS Yöntemi, Karadeniz Konteyner Limanları, Verimlilik Analizi.
Productivity Analysis of Black Sea Container Ports by Using Integrated Entropy and EATWOS Methods

\begin{abstract}
The Black Sea region is an extremely important region for global trade. Approaches such as short sea shipping and marine highways, which are on the agenda of European Union lead to increase the importance of Black Sea container ports by day by. Thus, performance of seaports of the region will be important factors, which can affect to their development and improvement that will be happened. Because effectivity of seaports may be effected by many factors, it is needed to use the MCDM methodologies can provide a systematic and structural solution way for evaluation. In this study, a hybrid model, which integrated the entropy and EATWOS methods is proposed to make productivity analysis of Black sea container ports. It is expected that obtained results from this study may have a usable characteristic by investors and public authorities in addition to actors, that placed in the logistics processes
\end{abstract}

Keywords: Entropy method, EATWOS Method, Black Sea Container Ports, Productivity Analysis.

\section{Giriş}

Dünya deniz ticareti günden güne gelişim göstermektedir. Bazı dönemlerde kısmi bir daralma söz konusu olsa da denizcilik sektörü gelişimini bu dönemlerde de sürdürmekte, deniz taşımacılığında kullanılan gemilerin kapasiteleri ile teknik özellikleri açısından kayda değer ilerlemeler kaydedilirken, uluslararası denizyolu taşımacılığının en önemli bileşenlerinden birisi olan limanlar da sürekli bir gelişim göstermektedir. Limanlar gereksinimlere cevap verebilmek üzere, sürekli olarak elleçleme, depolama ve operasyon kabiliyetlerini geliştirmeye çalışırlarken, aynı zamanda hizmet talebinde bulunan müşteri ve kullanıcıların potansiyel tüm gereksinimlerini karşılamak üzere ürettikleri hizmetleri çeşitlendirmenin yollarını aramaktadırlar.

Günümüzde limanlar geçmiştekinden farklı olarak çok amaçlı liman olabilme hedefine odaklanmaktadır. Geçmişte limanlar sadece dökme yük, Kuruyük, konteyner limanları olarak kendilerini konumlandırırken, günümüzde bütün yük türlerine farklı perspektifler çerçevesinde hizmet verebilir hale gelmeye çalışmaktadırlar.

\footnotetext{
${ }^{1}$ Dr. Öğr. Üyesi, Kadir Has Üniversitesi, UBF, Uluslararası Ticaret ve Lojistik Bölümü. omer.gorcun@khas.edu.tr, Yazar ORCID bilgisi: http://orcid.org/0000-0003-3850-6755
} 
Bir diğer açıdan, limanların özellikleri ve teknik kapasiteleri ne olursa olsun operatörler, taşımacılar ve lojistik faaliyet gösteren aktörlerin tercihleri son derece önem arz eden bir faktördür. Dolayısıyla limanın etkinliği ve verimliliği kullanıcı tercihleri ile son derece bağlantılı bir konudur. Aynı zamanda kullanıcılar tercih edecekleri bir limanın kendilerine en yüksek fayda ve en düşük maliyeti sağlamasının yanı sıra, en yüksek lojistik performansı yaratacak alternatif olmasına da önem vermektedirler. Bu açıdan bakıldığında limanların yaratacakları etkinlik ve verimlilik düzeyi limanın tercih edilebilirliğini de büyük ölçüde etkileyebilecek ve limanın gelişmesi ve büyümesi için de bir itici güç olabilecektir.

Günümüzün yüksek rekabet koşullarında bir limanın kendisine ilişkin etkinlik ve verimlilik düzeyinin farkında olması rekabet gücünü artırmaya yönelik atacağı adımlarda da daha rasyonel kararlar alabilmesini ve kaynak kullanımını daha gerçekçi bir perspektifte yapabilmesini olanaklı hale getirebilecektir. Aynı zamanda limanın rekabet potansiyeline de büyük ölçüde ışık tutabilecektir. Ek olarak çalışmanın çıktılarından sadece liman işletmeleri değil, taşıma operatörleri, lojistik işletmeler, denizcilik ve gemi işletmeleri, kamu otoriteleri ve yatırımcılar gibi aktörlerin de faydalanabileceği öngörülmektedir. Nihai olarak akademik alanda yer alacak liman verimliliği ile ilgili çalışmalara da ışık tutabileceği, aynı zamanda literatürde görülen boşluğun giderilmesi ile ilgili katkı sağlayabileceği değerlendirilmektedir.

Limanların performansları, verimlilikleri ve etkinliklerine etki eden çok sayıda değişken ile faktör bulunmaktadır. Bu faktörlerin tümü birlikte değerlendirmeye alınarak, karar vericilerin sezgisel bir yaklaşımla bir sonuca varabilmeleri olanaklı görülmemektedir. Dolayısıyla limanların verimlilik analizi özünde çok kriterli bir karar verme problemi olarak tanımlanabileceği için, gerçekçi ve kullanılabilir sonuçlar elde edebilmek amacıyla çok kriterli karar verme yöntemlerinin kullanılması zorunluluk olarak ortaya çıkmaktadır. Bu çalışmada çok kriterli karar verme yöntemi olarak, entropi ve EATWOS yöntemlerinin entegre edilmesi ile oluşturulan hibrid bir model önerilmiştir. Model üçü hazırlık, sekizi ise uygulama adımı olmak üzere toplam on bir adımdan oluşmaktadır. Uygulama adımlarının ilk dördünde entropi yöntemi kullanılarak değerlendirmeye alınan faktörler için ağılık değerleri hesaplanırken, sonraki dört adımda EATWOS yönteminin adımları kullanılarak her bir karar noktasının verimlilik değeri hesaplanmış ve değerlendirilen alternatifler verimlilik değerlerine göre sıralandırılmıştır.

Bu çalışma toplamda beş bölümden oluşmaktadır. Birinci bölüm olan giriş kısmında konunun genel çerçevesi tanımlanırken, ikinci bölümde konu ile ilgili literatür taraması yapılmış, üçüncü aşamada kullanılan metot ve adımları açıklanırken, dördüncü aşamada seçilen hibrid modelin test edildiği nümerik bir analiz gerçekleştirilmiş, beşinci ve son aşamada ise elde edilen sonuçlar tartışılmıştır.

\section{Literatür Taraması}

Konu ile ilgili literatür taraması yapılmadan önce kapsamın belirlenmesi ve ilgili literatür buna göre sınıflandırılmıştır. Bu perspektifte literatür taraması ile ilgili olarak, öncelikle liman verimlilik analizi ile ilgili çalışmalar gözden geçirilerek bunlar arasında çok kriterli karar verme yöntemlerinin kullanıldığı çalışmalara odaklanılmıştır. Ek olarak seçilen modelin kullanıldığı liman verimliliği ile ilgili bir çalışmanın olup olmadığı gözden geçirilmiştir. Son olarak, seçilen model dahil olmak üzere bu modeli oluşturan yöntemlerin en az birini kullanan çalışmalar taranmıştır.

Genel olarak değerlendirildiğinde liman verimliliği ile ilgili çok sayıda çalışmaya rastlanılmaktadır. Bu çalışmaların önemli bir bölümü limanların etkinliğine odaklanan çalışmalardır. 
Cullinane, Song, Ji ve Wang (2004) Veri Zarflama Analizi (VZA) tekniği kullanarak, limanların etkinliğini analiz ederken, bir başka çalışmada Cullinane, Song ve Ji (2006) limanların etkinliği ile ilgili olarak VZA tekniği ile Skolastik Sınır Analizi (SFA) yöntemlerini karşılaştırmışlardır. Tongzon ve Heng (2005) çalışmalarında liman özelleştirmelerinin liman etkinliğine etkilerini gözden geçirirken, Cullinane ve Wang (2006) kesitsel veri zaflama tekniği ile Avrupa limanlarının verimliliklerini analiz etmişlerdir. Stahlbock ve Voß (2008) konteyner terminalleri ile ilgili gerçekleştirilen yöneylem araştırmalarına dayanan çalışmaları gözden geçirdikleri bir literatür çalışması yapmışlardır.

Barros (2003) çalışmasında VZA tekniğinden faydalanarak Portekiz limanlarının etkinliğini değerlendirirken, Barros ve Athanassiou (2005) benzer bir çalışmayı Yunanistan limanlarını da kapsayacak bir biçimde gerçekleştirmişlerdir. K Cullinane ve Song (2006) Avrupa limanlarının göreli etkinliklerini VZA tekniği kullanarak analiz ederlerken, Panayides, Maxoulis ve Wang (2009) limanlarda ekonomik verimlilik ölçümü için VZA tekniğini kullandıkları bir çalışma gerçekleştirmişlerdir. Wang ve Cullinane (2015) tedarik zincirlerine etkileri açısından Avrupa konteyner limanlarının etkinliklerini analiz etmişler, Song ve Yeo (2004) AHP yöntemi kullanarak Çin konteyner limanlarının rekabet güçlerini değerlendirmişlerdir. Notteboom, Coeck ve Van Den Broeck (2000) Bayesian stokastik sınır modelleri ile konteyner terminallerinin nispi etkinliğinin ölçülmesine yönelik bir çalışma gerçekleştirmişler. Cullinane, Song ve Wang (2005) konteyner liman üretim verimliliğini tahmin etmeye yönelik olarak matematiksel programlama yaklaşımlarını kullanmışlar, Notteboom (2005) tüm dünyada yer alan konteyner limanlarını gözden geçirmiş, Roll ve Hayuth (1993) ise VZA yöntemini kullanarak limanların performanslarını analiz etmişlerdir. Cullinane, Song ve Gray (2002) idari ve mülkiyet yapılarını göz önüne alarak stokastik sınır modeli kullanmışlar ve Asya'daki ana konteyner terminallerinin verimliliğini analiz etmişlerdir.

Parola ve Sciomachen (2005) simülasyon modelleri kullanarak intermodal konteyner limanlarında büyüme potansiyelini simüle etmişlerdir. Lirn, Thanopoulou ve Beynon (2004) küresel bir bakış açısıyla aktarma limanı seçiminde AHP yöntemini kullanmışlar, Clark, Dollar ve Micco (2004) liman verimliliğini denizyolu taşımacılığı maliyetleri açısından değerlendirmişlerdir. Sánchez, Hoffmann, Micco ve Pizzolitto (2003) uluslararası denizyolu taşımacılık maliyetleri perspektifinde liman verimliliklerini analiz etmişlerdir. Wu ve Goh (2010) gelişmekte olan ülkelerde liman verimliliklerini değerlendirmişler, Tongzon (2001) VZA tekniği kullanarak Avustralya limanlarının verimliliklerini ölçmüştür. Wiegmans ve Hoest (2008) tarafından yapılan çalışmada uzak mesafe deniz taşımacılığında kullanılan limanların seçimi ile ilgili olarak çok kriterli karar verme teknikleri kullanılmıştır. Cullinane ve Wang (2010) panel veri analizi yaklaşımı ile VZA yöntemlerini birlikte kullanarak konteyner limanları için etkinlik analizi yaparken, K Bichou ve Gray (2204) liman performans ölçütleri için bir lojistik ve tedarik zinciri yaklaşımı geliştirmişlerdir. Malchow ve Kanafani (2004) çalışmalarında liman seçimi için bir analiz gerçekleştirlerken, Notteboom ve Rodrigue (2005) limanların bölgeselleşmesi üzerinde durmuşlar, Valentine ve Gray (2001) VZA tekniğini kullanarak liman etkinliğini analiz etmişlerdir.

Wang, Song ve Cullinane (2003) konteyner limanlarının etkinlik analizi için VZA yöntemi ile Parametrik Olmayan Hull (FDH) yöntemlerini karşılaştırmalı olarak kullanmış, Yeo, Roe ve Dinwoodie (2008) Kore ve Çin limanlarının rekabetçilik düzeylerini karşılaştırmış, Park ve De (2015) çalışmalarında limanların etkinliklerinin ölçülebilmesi için alternatif bir yaklaşım ileri sürmüşlerdir. 
Trujillo ve Tovar (2007) çalışmalarında Avrupa limancılık endüstrisinin ekonomik etkinliğini değerlendirken, Notteboom (2010) Avrupa konteyner liman sisteminde çok limanlı bölgeselleşme yaklaşımını irdelemiştir. Öte yandan, Anderson, Park ve Chang (2008) Busan ve Şangay limanlarını karşılaştırdıkları çalışmalarında oyun teorisini kullanarak hub limanlar arasında oluşan rekabeti analiz etmişler, Langen (2004) limanlarda etkinliği değerlendirmek üzere kümeleme yaklaşımını gözden geçirmiştir. Lam ve Yap (2011) tedarik zinciri sisteminde limanlar arası entegreasyonu analiz etmişler, entegrasyon düzeyinin liman etkinliği üzerinde etkilerini incelemişlerdir.

Limanların etkinlik ve verimliklerine odaklanan çalışmalar içerisinde entropi ve EATWOS yaklaşımlarını entegre olarak kullanarak bir analiz gerçekleştiren çalışmaya ratlanılmadığı gibi, her iki yaklaşımın ayrı ayrı kullanıldığı bir çalışma mevcut değildir. Çalışmaların çok önemli bir bölümü Veri Zarflama Analizi (VZA) yaklaşımı ile gerçekleştirilirken, çalışmaların bir kısmında da stokastik sınır modellerinin kullanıldığı görülmektedir. Öte yandan VZA yöntemini kullanan çalışmalar gözden geçirildiğinde; en fazla altı girdi ve dört çıktı faktörü kullanıldığı, önemli bir kısmında da üç girdi, iki çıktı faktörünün değerlendirmeye alındığı görülmektedir.

Bu perspektifte değerlendirildiğinde dikkate alınan girdi ve çıktı faktörleri son derece sınırIıdır. Dolayısıyla sonuca etki edebilecek bir takım faktörlerin dışarıda bırakılması analizin etkinliğini azaltmakta, elde edilen çıktıların kullanılabilirlik değerini düşürebilmektedir. Bu nedenle bu çalışmada VZA yöntemine kıyasla daha fazla sayıda faktörün analiz edilmesine olanak sağlayabilecek bir yöntem olan EATWOS yaklaşımı tercih edilmiştir. Bu yöntemin tercih edilmesinin bir başka nedeni ise karar vericiler tarafından kolayca kullanılabilecek bir yöntem olmasının yanı sıra, yöntemin uygulanması ile ilgili olarak bir yazılım ya da programa gereksinim duyulmaması olarak ifade edilebilir. Bu yöntem ile yapılan çalışmalar gözden geçirildiğinde;

Peters, Zelewski ve Burns (2012) çalışmalarında EATWOS yöntemini ileri sürmüşler ve uygulama adımlarını göstermişlerdir. Bandar, Singh ve Issar (2014) çalışmalarında satıcıların performansını EATWOS yöntemi kullanarak değerlendirmişlerdir. Özbek (2015a) Türkiye'deki bireysel emeklilik şirketlerinin verimlilik değerlerini analiz ederken EATWOS yöntemini kullanmıştır. Aynı yöntem kullanılarak yapılan çalışmalar arasında Kumar, Singh, Verma ve Sonal (2016) tarafından Hindistan birinci lig oyuncularının performansı ölçülürken, Özbek (2015b) bir başka çalışmasında sivil toplum örgütlerinin performansını değerlendirirmiş, bir başka çalışmasında hayırsever kuruluşların (Özbek 2017a) ve Türk Kızılay'ın (Özbek 2015c), altın madencilik işletmelerinin (Özbek 2016), ilkokul öğretmenlerinin yardım sandıklarının (Özbek 2017b) verimliliklerini analiz etmiştir. Çanakçıŏ̆lu (2019) çalışmasında BIST de yer alan Çimento sekeötrünü Entropi tabanlı EATWIOS bütünleşik yaklaşımı ile inceleyerek, finansal performanslarını değerlendirmiştir. Soni, Singh ve Banwet (2016) çalışmalarında EATWOS yöntemini kullanarak Hindistan enerji sektörünün verimliliğini gözden geçirmişlerdir.

Öte yandan EATWOS yöntemini kullanan çalışmaların büyük kısmında faktör ağırlıklarını ölçmek üzere Dephi tekniğinin yanı sıra, Özellikle Özbek tarafından Veri Zarflama Tekniği (VZA) tercih edilmiş, herhangi bir çalışmada Entropi ve EATWOS yöntemlerinin entegre olarak kullanıldığı hibrid bir modele rastlanılmamıştır. Bu kapsamda bu çalışma yeni bir hibrid model önermenin yanı sıra, özellikle denizyolu taşımacılı̆̆ı, konteyner limanları ve lojistik alanlarına ilişkin literatüre kayda değer ölçekte katkıda bulunma amacındadır. Aynı zamanda çalışmanın modeline ek olarak elde edilen bulgular daha sonraki çalışmalara da ışık tutabilecektir. 


\section{Materyal ve Metot}

Bu çalışmada Karadeniz konteyner limanlarının verimlilik analizi için entropi ve EATWOS yöntemlerinin entegre edildiği hibrid bir model oluşturulmuştur. Söz konusu model uygulama olarak sekiz adımdan oluşmakta, uygulama öncesinde araştırma sürecinin tasarımı için üç aşamadan oluşan bir hazırlık süreci de tanımlanmıştır. Hazırlık sürecinin başlangıcında öncelikli olarak problem tanımlanmış, problemin çözülmesi için kullanılacak hibrid model belirlenmiştir.

Hazırlık sürecinin ikinci aşamasında denizcilik sektöründe en az on beş yıl üst düzey yönetici olarak çalışmış profesyoneller arasından seçilen yedi üyeli bir çalışma grubu oluşturulmuştur. Çalışma grubu ile gerçekleştirilen toplantılarda çalışmanın belirlenen aşamaları gözden geçirilirken, aynı zamanda çalışma grubu bir danışma kurulu fonksiyonu da üstlenmiştir. Üçüncü aşamada ise çalışma grubu ile birlikte analizde kullanılacak girdi ve çıktı faktörleri saptanmıştır. Illk üç aşama tamamlandıktan sonra seçilen modelin uygulama aşamasına geçilmiştir. Uygulama sürecinde ilk dört aşama entropi yönteminin uygulama adımları olup, her bir faktör için kullanılacak sayısal değerler değerlendirme alınan limanların yayınladıkları resmi istatistikler, yıllık faaliyet raporları, finansal raporlar ve bağımsız denetçi raporları gibi kaynakların yanı sıra, Uluslararası Denizcilik Örgütü, Deniz Ticaret Odaları gibi resmi kuruluşların istatistiklerinden elde edilmiş, öte yandan elde edilemeyen sınırlı düzeyde veriler limanların yetkili otoriteleri ile kurulan irtibatlar sonucunda sağlanmıştır. Bu şekilde çeşitli kaynaklardan elde edilen veriler kullanılarak belirlenen girdi ve çıktı faktörlerinin ağılıkları hesaplanmıştır.

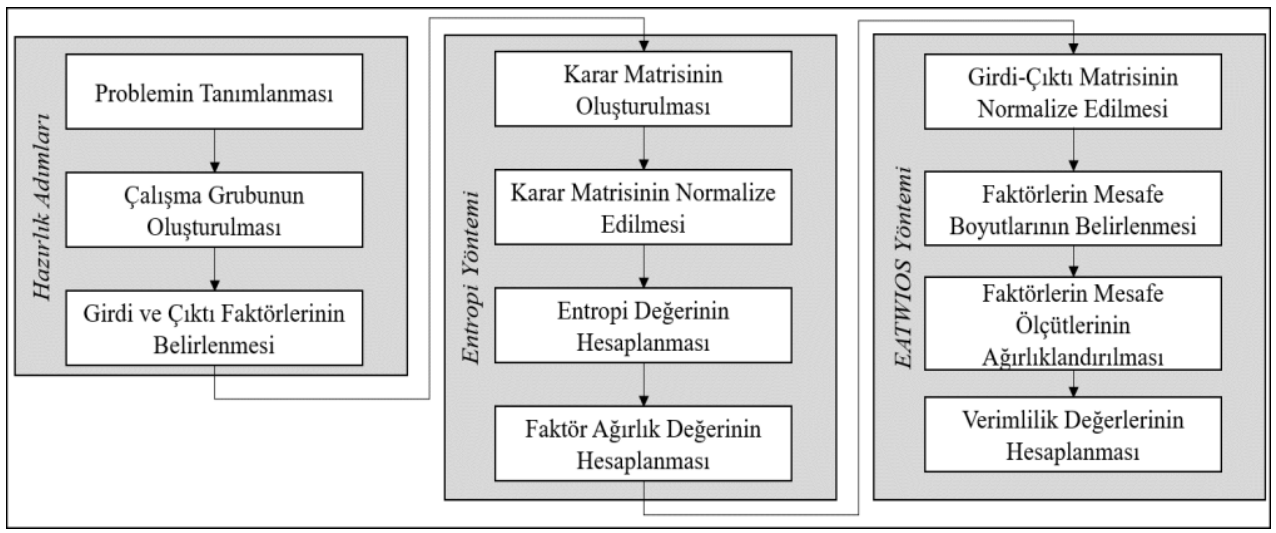

Şekil 1. Hibrid modelin işlem adımları

Sonraki dört adımda Karadeniz bölgesinde yer alan limanların verimlilik analizi EATWOS yönteminin adımları kullanılarak gerçekleştirilmiş ve söz konusu limanlar verimlilik skorlarına göre sıralandırımışlardır.

\subsection{Entropi Yöntemi ve Uygulama Adımları}

Entropi yöntemi son derece geniş bir uygulama alanına sahip bir yöntemdir. Entropi yönteminin sağladığı en önemli avantajların başında karar alıcıların sezgisel yaklaşım ve sözel yargılarına başvurulması gibi zorunlulukları ortadan kaldırması gelmektedir. Bu yöntem sayesinde zaman zaman tutarsız olabilen karar alıcıların yaklaşımlarına dayanan AHP, SWARA, Delphi vb. yaklaşımların kullanılmasına gereksinim ortadan kalkmakta, elde edilen sonuçlar daha yüksek düzeyde tutarlılık gösterebilmektedir. Yöntem dört adımda uygulanmakta, nihai olarak belirlenen bütün girdi ve çıktı faktörlerinin ağılık değerleri hesaplanmaktadır. 
Adım-1 Karar Matrislerinin Oluşturulması: Seçilen hibrid modelin ilk aşamasında elde edilen veriler kullanılarak eşitlik 1 de gösterilen matrisler oluşturulmaktadır. Matris $X$ girdi faktörlerini gösterirken, matris $Y$ ise çıktı faktörlerini ifade etmektedir. Matris $X$ de gösterilen değerlerin en azlanması, matris $Y$ de gösterilen değerlerin en çoklanması elde edilecek faydanın, dolayısıyla verimliliğin artması ile sonuçlanması beklenmektedir. Dolayısıyla matris $X$ de yer alan girdi faktörleri minimizasyon yönlü, matris $Y$ de yer alan çıktı faktörleri ise maksimizasyon yönlü faktörlerdir.

$$
\begin{gathered}
\mathrm{X}=\left[\begin{array}{cccccc}
x_{11} & x_{12} & \ldots & x_{1 k} & \ldots & x_{1 K} \\
x_{21} & x_{22} & \ldots & x_{2 k} & \ldots & x_{2 K} \\
\vdots & \vdots & \ddots & \vdots & \ldots & \vdots \\
x_{i 1} & x_{i 2} & \ldots & x_{i k} & \ldots & x_{i K} \\
\vdots & \vdots & \ldots & \vdots & \ddots & \vdots \\
x_{l 1} & x_{l 2} & \ldots & x_{l k} & \ldots & x_{l K}
\end{array}\right] ; \mathrm{Y}=\left[\begin{array}{cccccc}
y_{11} & y_{12} & \ldots & y_{1 j} & \ldots & y_{1 J} \\
y_{21} & y_{22} & \ldots & y_{2 j} & \ldots & y_{2 J} \\
\vdots & \vdots & \ddots & \vdots & \ldots & \vdots \\
y_{i 1} & y_{i 2} & \ldots & y_{i j} & \ldots & y_{i J} \\
\vdots & \vdots & \ldots & \vdots & \ddots & \vdots \\
y_{l 1} & y_{l 2} & \ldots & y_{l j} & \ldots & y_{l J}
\end{array}\right] \\
\forall i=1,2 \ldots, l ; \forall k=1,2 \ldots, K ; \quad \forall i=1,2 \ldots, l ; \forall j=1,2 \ldots, J
\end{gathered}
$$

Adım-2 Karar Matrislerinin Normalize Edilmesi: Girdi faktörlerinin yer aldığı karar matrisi $X$ in tüm elemanları eşitlik 2a kullanılarak, çıktı faktörlerinin yer aldığı karar matrisi Y'nin elemanları ise eşitlik $2 b$ kullanılarak normalize edilmektedir. Normalizasyon işleminde her bir matris elemanı kendi sütün toplamına bölünerek normalize edilmektedir.

$$
\begin{aligned}
x^{*}{ }_{i j} & =\frac{x_{i j}}{\sum_{i=1}^{m} x_{i j}} \\
y^{*}{ }_{i j} & =\frac{y_{i j}}{\sum_{i=1}^{m} y_{i j}}
\end{aligned}
$$

Eşitlik $2 a$ ve $2 b$ yardımıyla matris elemanları normalize edildikten sonra eşitlik 3 de gösterilen normalize matrisler oluşturulmaktadır.

$$
\begin{aligned}
& X^{*}=\left[\begin{array}{cccccc}
x^{*}{ }_{11} & x^{*}{ }_{12} & \ldots & x^{*}{ }_{1 k} & \ldots & x^{*}{ }_{1 K} \\
x^{*}{ }_{21} & x^{*}{ }_{22} & \ldots & x^{*}{ }_{2 k} & \ldots & x^{*}{ }_{2 K} \\
\vdots & \vdots & \ddots & \vdots & \ldots & \vdots \\
x^{*}{ }_{i 1} & x^{*}{ }_{i 2} & \ldots & x^{*}{ }_{i k} & \ldots & x^{*}{ }_{i K} \\
\vdots & \vdots & \ldots & \vdots & \ddots & \vdots \\
x^{*}{ }_{l 1} & x^{*}{ }_{l 2} & \ldots & x^{*}{ }_{l k} & \ldots & x^{*}{ }_{l K}
\end{array}\right] ; Y^{*}=\left[\begin{array}{cccccc}
y^{*}{ }_{11} & y^{*}{ }_{12} & \ldots & y^{*}{ }_{1 j} & \ldots & y^{*}{ }_{1 J} \\
y^{*}{ }_{21} & y^{*}{ }_{22} & \ldots & y^{*}{ }_{2 j} & \ldots & y^{*}{ }_{2 J} \\
\vdots & \vdots & \ddots & \vdots & \ldots & \vdots \\
y^{*}{ }_{i 1} & y^{*}{ }_{i 2} & \ldots & y^{*}{ }_{i j} & \ldots & y^{*}{ }_{i J} \\
\vdots & \vdots & \ldots & \vdots & \ddots & \vdots \\
y^{*}{ }_{l 1} & y^{*}{ }_{l 2} & \ldots & y^{*}{ }_{l j} & \ldots & y^{*}{ }_{l J}
\end{array}\right] \text { (3) } \\
& \forall i=1,2 \ldots, l ; \forall k=1,2 \ldots, K ; \quad \forall i=1,2 \ldots, l ; \forall j=1,2 \ldots, J
\end{aligned}
$$

Adım-3 Faktörlere iliş̧kin Entropi Değerinin Hesaplanması: Girdi ve çıktı faktörleri için entropi değeri hesaplanırken, eşitlik $4 a$ ve $4 b$ kullanılmaktadır.

$$
\begin{aligned}
& e^{*}{ }_{i j}=x^{*}{ }_{i j} \cdot\left((\ln ) x^{*}{ }_{i j}\right) \\
& e^{-}{ }_{i j}=y^{*}{ }_{i j} \cdot\left((\ln ) y^{*}{ }_{i j}\right)
\end{aligned}
$$

Matrislerin her bir elamanın entropi değeri hesaplandıktan sonra eşitlik 5 de olduğu gibi girdi ve çıktı faktörlerinin entropi değerlerini gösteren matrisler oluşturulmaktadır. 


$$
\begin{aligned}
& E^{*}=\left[\begin{array}{cccccc}
e^{*}{ }_{11} & e^{*}{ }_{12} & \ldots & e^{*}{ }_{1 k} & \ldots & e^{*}{ }_{1 K} \\
e^{*}{ }_{21} & e^{*}{ }_{22} & \ldots & e^{*}{ }_{2 k} & \ldots & e^{*}{ }_{2 K} \\
\vdots & \vdots & \ddots & \vdots & \ldots & \vdots \\
e^{*}{ }_{i 1} & e^{*}{ }_{i 2} & \ldots & e^{*}{ }_{i k} & \ldots & e^{*}{ }_{i K} \\
\vdots & \vdots & \ldots & \vdots & \ddots & \vdots \\
e^{*}{ }_{l 1} & e^{*}{ }_{l 2} & \ldots & e^{*}{ }_{l k} & \ldots & e^{*}{ }_{l K}
\end{array}\right] ; E^{-}=\left[\begin{array}{cccccc}
e^{-}{ }_{11} & e^{-}{ }_{12} & \ldots & e^{-}{ }_{1 k} & \ldots & e^{-}{ }_{1 K} \\
e^{-}{ }_{21} & e^{-}{ }_{22} & \ldots & e^{-}{ }_{2 k} & \ldots & e^{-}{ }_{2 K} \\
\vdots & \vdots & \ddots & \vdots & \ldots & \vdots \\
e^{-}{ }_{i 1} & e^{-}{ }_{i 2} & \ldots & e^{-}{ }_{i k} & \ldots & e^{-}{ }_{i K} \\
\vdots & \vdots & \ldots & \vdots & \ddots & \vdots \\
e^{-}{ }_{l 1} & e^{-}{ }_{l 2} & \ldots & e^{-}{ }_{l k} & \ldots & e^{-}{ }_{l K}
\end{array}\right] \\
& \forall i=1,2 \ldots, l ; \forall k=1,2 \ldots, K ; \quad \forall i=1,2 \ldots, l ; \forall j=1,2 \ldots, J
\end{aligned}
$$

Bütün elemanların entropi değeri hesaplandıktan sonra, eşitlik $6 a$ ve $6 \mathrm{~b}$ kullanılarak her bir faktör için entropi değeri hesaplanmaktadır.

$$
\begin{aligned}
{E^{*}}_{i j} & =\left(\frac{-1}{\ln (m)}\right) \sum_{i=1}^{m}\left[x_{i j}^{*} \cdot \ln x_{i j}^{*}\right] ; \forall j \\
E^{-}{ }_{i j} & =\left(\frac{-1}{\ln (m)}\right) \sum_{i=1}^{m}\left[y^{*}{ }_{i j} \cdot \ln y_{i j}^{*}\right] ; \forall j
\end{aligned}
$$

Bu adımın son aşamasında dj olarak tanımlanan belirsizlik değeri eşitlik 7a ve 7b kullanılarak hesaplanmaktadır.

$$
\begin{aligned}
& d^{*}{ }_{i j}=1-E^{*}{ }_{i j} ; \forall j \\
& d^{-}{ }_{i j}=1-E^{-}{ }_{i j} ; \forall j
\end{aligned}
$$

Adım-4 Faktörlerin Ağırıı Değerlerinin Hesaplanması: Entropi yönteminin son adımında eşitlik $8 \mathrm{a}$ ve $8 \mathrm{~b}$ kullanılarak değerlendirmeye alınan her bir girdi ve çıktı faktörünün ağırlık değeri belirlenmektedir.

$$
\begin{aligned}
w^{*}{ }_{i j} & =\frac{d^{*}{ }_{i j}}{\sum_{i=1}^{m} d^{*}{ }_{i j}} ; \forall j \\
w^{-}{ }_{i j} & =\frac{d^{-}{ }_{i j}}{\sum_{i=1}^{m} d^{-}} ; \forall j
\end{aligned}
$$

\subsection{EATWOS Yöntemi ve Uygulama Adımları}

Girdi ve Çıktıların Tatminine Dayalı Etkinlik Analizi Tekniği (EATWOS) verimlilik analizi tekniği olarak ölçülmek istenen karar noktalarına ilişkin girdi ve çıktı faktörlerine odaklanan bir metodolojidir. Metodoloji toplamda dört uygulama adımından oluşmakta, uygulanan dört adım sonucunda karar noktalarının verimlilikleri hesaplanabilmektedir. Yöntem aynı zamanda değerlendirilen karar noktalarının verimliliklerinin karşılaştırılması ile ilgili olarak da karar alıcılara olanak sağlamaktadır.

Adım-5 Girdi ve Çıktı Faktörlerinin Normalizasyonu: Beşinci adım entropi yönteminin adımları tamamlanarak, bütün faktörler ağırlıklandırıldıktan sonra değerlendirmeye alınan karar noktalarının verimlilik analizinin gerçekleşeceği EATWOS yönteminin ilk aşamasıdır. Entropi yönteminin ilk aşamalarında oluşturulan karar matrisleri entropi yönteminde gerçekleştirilen normalizasyon işleminden farklı olarak, eşitlik 9a ve 9b yardımıyla normalize edilmektedir. Girdi faktörlerinin yer aldığı matris normalize edilirken, eşitlik 9a, çıktı faktörlerinin bulunduğu matris normalize edilirken eşitlik $9 \mathrm{~b}$ kullanılmaktadır. 


$$
\begin{aligned}
& s_{i j}=\frac{x_{i j}}{\sqrt{\sum_{i=1}^{m}\left(x_{i j}\right)^{2}}} ; \forall j \\
& r_{i j}=\frac{y_{i j}}{\sqrt{\sum_{i=1}^{m}\left(y_{i j}\right)^{2}}} ; \forall j
\end{aligned}
$$

Eşitlik 9a ve 9b kullanılarak her iki matrisin elemanları normalize edildikten sonra eşitlik 10 da gösterildiği gibi normalize matrisler oluşturulmaktadır.

$$
S=\left[\begin{array}{cccccc}
S_{11} & s_{12} & s_{13} & \ldots & \ldots & s_{1 j} \\
s_{21} & s_{22} & s_{23} & \ldots & \ldots & s_{2 j} \\
\vdots & \vdots & \ddots & \vdots & \ldots & \vdots \\
\vdots & \vdots & \ldots & \ldots & \ldots & \vdots \\
\vdots & \vdots & \ldots & \vdots & \ddots & \vdots \\
s_{l 1} & s_{l 2} & \ldots & \ldots & \ldots & s_{l j}
\end{array}\right] ; R=\left[\begin{array}{cccccc}
r_{11} & r_{12} & r_{13} & \ldots & \ldots & r_{1 j} \\
r_{21} & r_{22} & r_{23} & \ldots & \ldots & r_{2 j} \\
\vdots & \vdots & \ddots & \vdots & \ldots & \vdots \\
\vdots & \vdots & \ldots & \ldots & \ldots & \vdots \\
\vdots & \vdots & \ldots & \vdots & \ddots & \vdots \\
r_{l 1} & r_{l 2} & \ldots & \ldots & \ldots & r_{l j}
\end{array}\right]
$$

Adım-6 Faktörlerin Mesafe Ölçütlerinin Belirlenmesi: Girdi faktörlerinin mesafe ölçütlerinin belirlenmesi için eşitlik 11 a ve 11 bullanılmaktadır.

$s^{*}{ }_{k}=\min \left\{\vec{r}_{J}\right\} ; \forall j=1, \ldots, J$

$i p_{i k}=1+\left(s_{i k}-s^{*}{ }_{k}\right) ; \forall i=1, \ldots, k \quad \forall k=1, \ldots, K$

Çıktılar için eşitlik 11c kullanılarak her bir sütun için en büyük çıktı miktarı belirlenir. Ardından eşitlik 11d kullanılarak çıktı mesafe boyutları hesaplanır.

$r_{i j}=\max \left\{\overrightarrow{s_{k}}\right\} ; \forall k=1, \ldots, K$

$o p_{k}=1-\left(r_{j}^{*}-r_{i j}\right) ; \forall i=1, \ldots, l \quad \forall j=1, \ldots, J$

Bu işlemler tamamlandıktan sonra eşitlik 12 de gösterilen matris I ve matris 0 oluşturulmaktadır. Matris I girdi faktörlerini gösterirken, matris $O$ çıktı faktörlerini sembolize etmektedir.

$$
I=\left[\begin{array}{cccccc}
l_{11} & l_{12} & l_{13} & \ldots & \ldots & l_{1 j} \\
l_{21} & l_{22} & l_{23} & \ldots & \ldots & l_{2 j} \\
\vdots & \vdots & \ddots & \vdots & \ldots & \vdots \\
\vdots & \vdots & \ldots & \ldots & \ldots & \vdots \\
\vdots & \vdots & \ldots & \vdots & \ddots & \vdots \\
l_{l 1} & l_{l 2} & \ldots & \ldots & \ldots & l_{l j}
\end{array}\right] ; O=\left[\begin{array}{cccccc}
o_{11} & o_{12} & o_{13} & \ldots & \ldots & o_{1 j} \\
o_{21} & o_{22} & o_{23} & \ldots & \ldots & o_{2 j} \\
\vdots & \vdots & \ddots & \vdots & \ldots & \vdots \\
\vdots & \vdots & \ldots & \ldots & \ldots & \vdots \\
\vdots & \vdots & \ldots & \vdots & \ddots & \vdots \\
o_{l 1} & o_{l 2} & \ldots & \ldots & \ldots & o_{l j}
\end{array}\right]
$$

Adım-7 Mesafe Ölçütlerinin Ağırlıklandırılması: Bir önceki adımda bütün faktörler için belirlenen mesafe ölçütleri entropi yöntemi kullanılarak elde edilen faktör ağırlıkları ile çarpılarak ağırlıklandırılmış mesafe ölçütleri elde edilmektedir. Bunun için eşitlik $13 a$ ve $13 b$ den yararlanılmaktadır.

$$
\begin{gathered}
i^{*}{ }_{i j}=i p_{i k} \cdot w^{*}{ }_{i j} \\
o^{-}{ }_{i j}=i p_{i k .} w^{-}{ }_{i j}
\end{gathered}
$$


Eşitlikler kullanılarak tüm matris elemanları için mesafe ölçütleri belirlendikten sonra faktörlerin mesafe ölçütlerini gösteren, $I^{*}$ ve $0^{-}$matrisleri oluşturulmaktadır.

$$
I^{*}=\left[\begin{array}{cccccc}
l^{*}{ }_{11} & l^{*}{ }_{12} & l^{*}{ }_{13} & \ldots & \ldots & l^{*}{ }_{1 j} \\
l^{*}{ }_{21} & l^{*}{ }_{22} & l^{*}{ }_{23} & \ldots & \ldots & l^{*}{ }_{2 j} \\
\vdots & \vdots & \ddots & \vdots & \ldots & \vdots \\
\vdots & \vdots & \ldots & \ldots & \ldots & \vdots \\
\vdots & \vdots & \ldots & \vdots & \ddots & \vdots \\
l^{*}{ }_{l 1} & l^{*}{ }_{l 2} & \ldots & \ldots & \ldots & v_{l j}
\end{array}\right] ; O^{-}=\left[\begin{array}{cccccc}
O^{-}{ }_{11} & O^{-}{ }_{12} & o^{-}{ }_{13} & \ldots & \ldots & o^{-}{ }_{1 j} \\
O^{-}{ }_{21} & O^{-}{ }_{22} & o^{-}{ }_{23} & \ldots & \ldots & o^{-}{ }_{2 j} \\
\vdots & \vdots & \ddots & \vdots & \ldots & \vdots \\
\vdots & \vdots & \ldots & \ldots & \ldots & \vdots \\
\vdots & \vdots & \ldots & \vdots & \ddots & \vdots \\
o^{-}{ }_{l 1} & o^{-}{ }_{l 2} & \ldots & \ldots & \ldots & o^{-}
\end{array}\right]
$$

Adım-8 Verimlilik Değerlerinin Hesaplanması: Son adımda I* matrisinin her bir satırının toplamı bir karar noktasının girdi değerini, O- matrisinin her bir satır toplamı bir karar noktasının çıktı değerini vermektedir. Aynı satırda yer alan girdi toplamı çıktı toplamına bölündüğündesöz konusu alternatifin verimlilik değeri hesaplanabilmektedir. Bunun için eşitlik 15 kullanılmaktadır.

$F_{i}=\frac{\sum_{j=1}^{J} i^{*}{ }_{i j}}{\sum_{k=1}^{K} o^{-}{ }_{i j}}$

Eşitlik 15 kullanılarak tüm karar noktalarının verimlilik değerleri hesaplandıktan sonra en yüksek değerden başlanarak karar alternatifleri sıralandırılmaktadır. En yüksek değeri alan karar noktası en yüksek verime sahip alternatif olarak tanımlanabilmektedir.

\section{Karadeniz Konteyner Limanlarında Verimlilik Analizi}

Karadeniz bölgesinde yer alan konteyner limanlarının karşılaştırmalı olarak verimlilik ve etkinliklerinin analiz edilebilmesi için öncelikle değerlendirmeye alınacak konteyner limanları belirlenmiştir. Toplamda dokuz konteyner limanı analiz için seçilmiştir. Seçim sürecinde bu limanların bölgesel ve küresel ticarete yönelik konteyner limanları olması dikkate alınmıştır.

Sürecin devamında yedi kişiden oluşan çalışma grubu ile birlikte seçilen limanların etkinlik analizinde sayısal veri olarak kullanılacak girdi ve çıktı faktörleri saptanmıştır. Belirlenen faktörler bütün üyelerin ortak konsensüsü ile araştırma sürecine dahil edilmiştir. Bu perspektifte dokuz girdi faktörü belirlenirken, dört çıktı faktörü tespit edilmiştir.

Tablo 1. Limanlar, Girdi ve Çıktı Faktörleri

\begin{tabular}{|c|l|c|l|c|l|}
\hline \multicolumn{2}{|c|}{ Limanlar } & \multicolumn{2}{c|}{ Girdi } & \multicolumn{1}{c|}{ Çıktı } \\
\hline Kodu & \multicolumn{1}{|c|}{ Adı } & Kodu & \multicolumn{1}{c|}{ Adı } & Kodu & \multicolumn{1}{c|}{ Adı } \\
\hline P1 & Constanza & G1 & Personel Sayısı & Ç1 & Hizmet Alan Gemi Sayısı \\
\hline P2 & Varna & G2 & Rıhtım Uzunluğu & Ç2 & Yıllık Gelirler \\
\hline P3 & Burgaz & G3 & Derinlik (Draft) & Ç3 & Elleçlenen Yıllık TEU \\
\hline P4 & Odessa & G4 & Ekipman Sayısı & Ç4 & Elleçlenen Konteyner Sayısı \\
\hline P5 & Ilıcevsk & G5 & Depolama Alanı & & \\
\hline P6 & Samsun & G6 & Maks. Gemi Uzunluğu & & \\
\hline P7 & Trabzon & G7 & Liman Sahası & & \\
\hline P8 & Novorossysk & G8 & Düzenli Hat Sayısı & & \\
\hline P9 & Poti & G9 & Kapasite & & \\
\hline
\end{tabular}


Hazırlık sürecinde bütün faktörlerin sayısal değerleri resmi istatistikler, yıllık raporlar, finansal ve bağımsız denetçi raporlarının yanı sıra, son derece sınırlı olsa da elde edilemeyen ya da doğruluğundan tereddüt edilen veriler için değerlendirmeye alınan limanların idarelerinden doğrudan talep edilmiş, sonuç olarak gereken veriler tümüyle sağlanmıştır. Bu aşamadan sonra doğrudan belirlenen hibrid modelin uygulama aşamalarına geçilmiştir.

Adım-1 Karar Matrislerinin Oluşturulması: Elde edilen veriler çerçevesinde eşitlik 1 de gösterilen karar matrisleri oluşturulmuştur.

\begin{tabular}{|c|c|c|c|c|c|c|c|c|c|}
\hline & $G 1$ & $G 2$ & $G 3$ & G4 & G5 & G6 & \multicolumn{2}{|c|}{$G 8$} & $G 9$ \\
\hline$P 1$ & 6.000 & 540 & 8.5 & 8 & 25.000 & 540 & 260.130 & 10 & 700.00 \\
\hline$P 2$ & 1.623 & 5.775 & 11,5 & 51 & 62.630 & 500 & 443.997 & 8 & 220.000 \\
\hline$P 3$ & 1.300 & 365 & 11 & 10 & 31.350 & 280 & 442.410 & 7 & 200.000 \\
\hline$P 4$ & 3.500 & 10.200 & 13 & 55 & 202.000 & 330 & 1.410 .000 & 11 & 523.881 \\
\hline$P 5$ & 1.200 & 1.400 & 14,5 & 35 & 27.000 & 200 & 575.000 & 4 & 1. 150.000 \\
\hline$P 6$ & 766 & 1.756 & 10,5 & 7 & 50.000 & 152 & 445.000 & 12 & 250.000 \\
\hline P7 & 205 & 2.145 & 12 & 10 & 13.000 & 152 & 240.000 & 2 & 350.000 \\
\hline P8 & 2.861 & 562 & 13 & 18 & 62.200 & 282 & 872.000 & 5 & 740.000 \\
\hline$P 9$ & 1.200 & 2.900 & 16 & 20 & 69.000 & 150 & 512.300 & 8 & 185.000 \\
\hline$\sum$ & 18.655 & 25.643 & 110 & 214 & 542.180 & .586 & 5. 200.837 & 67 & 318.881 \\
\hline
\end{tabular}

Matris X girdi faktörlerinin değerlerini gösterirken, G1, G4 ve G8 olarak kodlanan girdi faktörleri adet, G2, G3 ve G6 olarak tanımlanan faktörler metre, G5 ve G7 ise metrekare cinsinden tanımlanmış değerlere sahiptir. Çıktı faktörlerine bakıldığında Ç1 ve Ç4 adet, Ç2 milyon Euro, Ç3 ise TEU cinsinden değerler almışlardır.

\begin{tabular}{|c|c|c|c|c|}
\hline \multicolumn{2}{|c|}{$P 1_{[13.365}$} & $\begin{array}{c}\text { C. } 2 \\
\mathbf{2 9 . 9 5 8 . 2 0 0 , 0 0}\end{array}$ & $\begin{array}{c}\text { Ç3 } \\
\mathbf{6 7 0 . 5 3 6}\end{array}$ & $\begin{array}{l}\text { CS4 } \\
\text { 413.253] }\end{array}$ \\
\hline$P 2$ & 7.865 & $37.513 .996,62$ & 134.000 & 121.712 \\
\hline P3 & 6.542 & $20.850 .000,00$ & 65.593 & 40.425 \\
\hline$P 4$ & 4.607 & $4.380 .236,93$ & 245.522 & 223.007 \\
\hline$P 5$ & 7000 & $15.930 .890,53$ & 123.078 & 75.853 \\
\hline$P 6$ & 2.984 & $3.233 .632,15$ & 65.928 & 59.882 \\
\hline P7 & 789 & $5.249 .253,85$ & 11.419 & 7.038 \\
\hline P8 & 1887 & 16.259.742, 50 & 224.070 & 203.522 \\
\hline$P 9$ & 1.300 & $5.953 .197,73$ & 82.039 & 50.561 \\
\hline$\sum$ & 46.339 & $185.793 .707,30$ & 1. 622.184 & 1. 195.253 \\
\hline
\end{tabular}

Adım-2 Karar Matrislerinin Normalize Edilmesi: Eşitlik 2a ve 2b kullanılarak her iki matrisin elemanları normalize edilmiş ve normalize matrisler oluşturulmuştur. 


\begin{tabular}{|c|c|c|c|c|c|c|c|c|c|}
\hline & $G 1$ & $G 2$ & G3 & $G 4$ & $G 5$ & $G 6$ & $G 7$ & $G 8$ & $G 9$ \\
\hline$P 2$ & 0,0870 & 0,2252 & 0,1045 & 0,2383 & 0,1155 & 0,1933 & 0,0854 & 0,1194 & 0,0509 \\
\hline P3 & 0,0697 & 0,0142 & 0,1000 & 0,0467 & 0,0578 & 0,1083 & 0,0851 & 0,1045 & 0,0463 \\
\hline$P 4$ & 0,1876 & 0,3978 & 0,1182 & 0,2570 & 0,3726 & 0,1276 & 0,2711 & 0,1642 & 0,1213 \\
\hline$=P 5$ & 0,0643 & 0,0546 & 0,1318 & 0,1636 & 0,0498 & 0,0773 & 0,1106 & 0,0597 & 0,2663 \\
\hline P6 & 0,0411 & 0,0685 & 0,0955 & 0,0327 & 0,0922 & 0,0588 & 0,0856 & 0,1791 & 0,0579 \\
\hline P7 & 0,0110 & 0,0836 & 0,1091 & 0,0467 & 0,0240 & 0,0588 & 0,0461 & 0,0299 & 0,0810 \\
\hline$P \varepsilon$ & 534 & 0,0219 & 0,1182 & 0,0841 & 0,1147 & $\mathbf{0}, 1$ & 677 & 0,0746 & 0,1713 \\
\hline$P C$ & 0643 & 0,1131 & 0,1455 & 0,0935 & 0,1273 & 0,0580 & 0,0985 & 0,1194 & 0,0428 \\
\hline
\end{tabular}

\begin{tabular}{|c|c|c|c|c|}
\hline$P 1$ & $\begin{array}{c}\text { Ç1 } \\
{[\mathbf{0 , 2 8 8 4}}\end{array}$ & $\begin{array}{c}\text { Ç2 } \\
\mathbf{0 , 4 1 1 3}\end{array}$ & $\begin{array}{c}\text { C.3 } \\
\mathbf{0 , 4 1 3 4}\end{array}$ & $\begin{array}{c}\text { Ç4 } \\
\mathbf{0 , 3 4 5 7}\end{array}$ \\
\hline$P 2$ & 0,1697 & 0,2019 & 0,0826 & 0,1018 \\
\hline$P 3$ & 0,1412 & 0,1122 & 0,0404 & 0,0338 \\
\hline$P 4$ & 0,0994 & 0,0236 & 0,1514 & 0,1866 \\
\hline$=P 5$ & 0,1511 & 0,0857 & 0,0759 & 0,0635 \\
\hline P6 & 0,0644 & 0,0174 & 0,0406 & 0,0501 \\
\hline P7 & 0,0170 & 0,0283 & 0,0070 & 0,0059 \\
\hline P8 & 0,0407 & 0,0875 & 0,1381 & 0,1703 \\
\hline D & 0281 & 0,0320 & 0,0506 & 0,042 \\
\hline
\end{tabular}

Adım-3 Faktörlere iliş̧kin Entropi Değerinin Hesaplanması: Eşitlik 4a ve 4b kullanılarak matrislerin her bir elamanı için entropi değeri hesaplanarak $E^{*}$ ve $\mathrm{E}$ - matrisleri oluşturulmuştur. Bunun için her bir normalize matris elamanı kendi logaritmik değeri ile çarpılmıştır. Eşitlik $6 a$ ve $6 \mathrm{~b}$ kullanılarak her bir faktör için entropi skoru hesaplanmış, her bir faktörün entropi skorunun 1'den farklı hesaplanarak belirsizlik değeri elde edilmiştir.

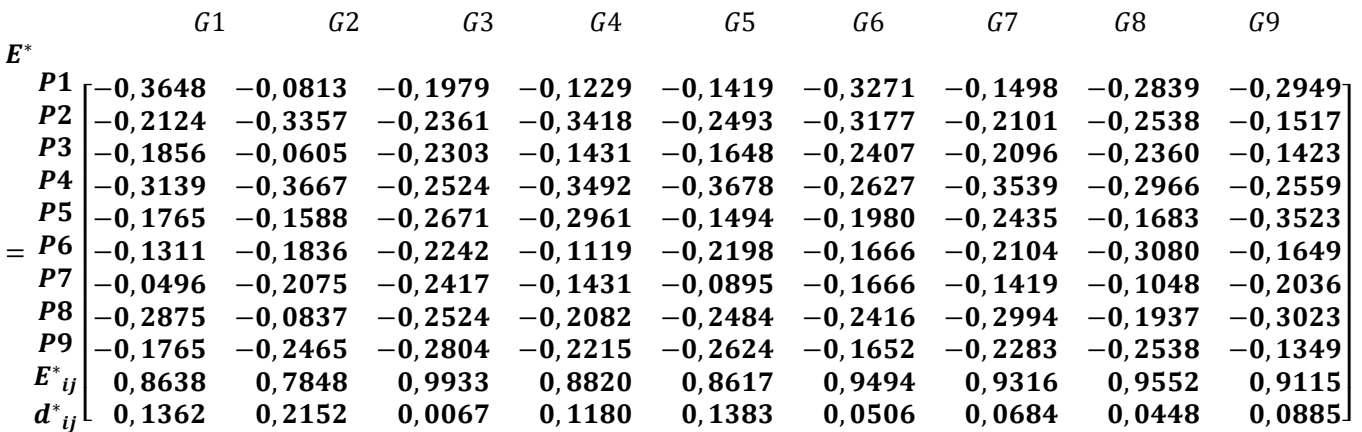

Girdi faktörleri için eşitlik 6a kullanılarak entropi değerleri hesaplanmış, ardından eşitlik 7a ile söz konusu faktörlerin her biri için belirsizlik değeri elde edilmiştir. Bu işlemlerin ardından eşitlik $6 \mathrm{~b}$ ve $7 \mathrm{~b}$ kullanılarak aynı işlemler çıktı faktörleri için de gerçekleştirilmiştir. 


\begin{tabular}{|c|c|c|c|c|}
\hline & Ç1 & Ç2 & Ç3 & Ç4 \\
\hline$P 1$ & {$[-0,3586$} & $-0,3654$ & $-0,3652$ & $-0,3672$ \\
\hline$P 2$ & $-0,3010$ & $-0,3230$ & $-0,2060$ & $-0,2326$ \\
\hline P3 & $-0,2764$ & $-0,2455$ & $-0,1297$ & $-0,1145$ \\
\hline$P 4$ & $-0,2295$ & $-0,0884$ & $-0,2858$ & $-0,3132$ \\
\hline$P 5$ & $-0,2855$ & $-0,2106$ & $-0,1957$ & $-0,1750$ \\
\hline$=P 6$ & $-0,1766$ & $-0,0705$ & $-0,1302$ & $-0,1500$ \\
\hline P7 & $-0,0693$ & $-0,1008$ & $-0,0349$ & $-0,0302$ \\
\hline P8 & $-0,1303$ & $-0,2132$ & $-0,2734$ & $-0,3014$ \\
\hline P9 & $-0,1003$ & $-0,1102$ & $-0,1509$ & $-0,1338$ \\
\hline $\boldsymbol{E}^{*}{ }_{i j}$ & 0,8773 & 0,7863 & 0,8064 & 0,8274 \\
\hline$d^{*}{ }_{i j}$ & 0,1227 & 0,2137 & 0,1936 & 0,1726 \\
\hline
\end{tabular}

Adım-4 Faktörlerin Ağırlık Değerlerinin Hesaplanması: Eşitlik 8a ve 8b kullanılarak her bir girdi ve çıktı faktörü için ağırlık değeri $(w)$ hesaplanmıştır.

\begin{tabular}{|c|c|c|c|c|c|c|c|c|c|c|c|c|c|}
\hline & $G 1$ & $G 2$ & \multicolumn{2}{|r|}{$G 3$} & \multicolumn{2}{|c|}{$G 4$} & \multicolumn{2}{|c|}{$G 5$} & \multicolumn{2}{|c|}{ G6 } & \multirow[t]{2}{*}{ G7 } & \multirow[t]{2}{*}{$G 8$} & \multirow[t]{2}{*}{$G 9$} \\
\hline $\boldsymbol{E}^{*}$ & & & & & & & & & & & & & \\
\hline$P 1$ & {$[-0,3648$} & $-0,0813$ & \multicolumn{2}{|c|}{$-0,1979$} & \multicolumn{2}{|c|}{$-0,1229$} & \multicolumn{2}{|c|}{$-0,1419$} & \multicolumn{2}{|c|}{$-0,3271$} & $-0,1498$ & $-0,2839$ & $-0,2949$ \\
\hline$P 2$ & $-0,2124$ & $-0,3357$ & \multicolumn{2}{|c|}{$-0,2361$} & \multicolumn{2}{|c|}{$-0,3418$} & \multicolumn{2}{|c|}{$-0,2493$} & \multicolumn{2}{|c|}{$-0,3177$} & $-0,2101$ & $-0,2538$ & $-0,1517$ \\
\hline P3 & $-0,1856$ & $-0,0605$ & \multicolumn{2}{|c|}{$-0,2303$} & \multicolumn{2}{|c|}{$-0,1431$} & \multicolumn{2}{|c|}{$-0,1648$} & \multicolumn{2}{|c|}{$-0,2407$} & $-0,2096$ & $-0,2360$ & $-0,1423$ \\
\hline$P 4$ & $-0,3139$ & $-0,3667$ & \multicolumn{2}{|c|}{$-0,2524$} & \multicolumn{2}{|c|}{$-0,3492$} & \multicolumn{2}{|c|}{$-0,3678$} & \multicolumn{2}{|c|}{$-0,2627$} & $-0,3539$ & $-0,2966$ & $-0,2559$ \\
\hline$P 5$ & $-0,1765$ & $-0,1588$ & \multicolumn{2}{|c|}{$-0,2671$} & \multicolumn{2}{|c|}{$-0,2961$} & \multicolumn{2}{|c|}{$-0,1494$} & \multicolumn{2}{|c|}{$-0,1980$} & $-0,2435$ & $-0,1683$ & $-0,3523$ \\
\hline$P 6$ & $-0,1311$ & $-0,1836$ & \multicolumn{2}{|c|}{$-0,2242$} & $-0,11$ & 119 & $-0,2$ & 98 & $-0,16$ & 666 & $-0,2104$ & $-0,3080$ & $-0,1649$ \\
\hline P7 & $-0,0496$ & $-0,2075$ & $-0,24$ & 417 & $-0,14$ & 431 & $-0,08$ & 395 & $-0,16$ & 666 & $-0,1419$ & $-0,1048$ & $-0,2036$ \\
\hline$P 8$ & $-0,2875$ & $-0,0837$ & $-0,25$ & 524 & $-0,2$ & 082 & $-0,2$ & 84 & $-0,2$ & 116 & $-0,2994$ & $-0,1937$ & $-0,3023$ \\
\hline$P 9$ & $-0,1765$ & $-0,2465$ & $-0,28$ & 304 & $-0,22$ & 215 & $-0,2$ & 24 & $-0,16$ & 652 & $-0,2283$ & $-0,2538$ & $-0,1349$ \\
\hline $\boldsymbol{w}^{*}{ }_{i j}$ & o, 1571 & 0,2483 & 0,00 & 98 & 0,13 & 362 & 0,1 & 96 & 0,0 & 583 & 0,0790 & 0,0517 & $0,1021]$ \\
\hline & & & & & Ç1 & & Ç2 & & Ç3 & & 4 & & \\
\hline & & & $P 1$ & {$[-\mathbf{0}$,} & 3586 & $-\mathbf{0}$ & 3654 & -0 , & 3652 & -0 , & $3672]$ & & \\
\hline & & & $P 2$ & -0 & 3010 & -0 & 3230 & -0 , & 2060 & -0 & 2326 & & \\
\hline & & & $P 3$ & -0 & 2764 & -0 & 2455 & -0 , & 1297 & -0 , & 1145 & & \\
\hline & & & $P 4$ & -0 & 2295 & -0 , & 0884 & -0 , & 2858 & -0 , & 3132 & & \\
\hline & & & $P 5$ & -0 & 2855 & -0 & 2106 & -0 & 1957 & -0 , & 1750 & & \\
\hline & & & $P 6$ & -0 & 1766 & -0 & 0705 & -0 & 1302 & -0 , & 1500 & & \\
\hline & & & P7 & -0 & 0693 & -0 & 1008 & -0 & 0349 & -0 , & 0302 & & \\
\hline & & & P8 & -0 , & 1303 & -0 & 2132 & -0 & 2734 & -0 , & 3014 & & \\
\hline & & & $P 9$ & -0 & 1003 & -0 & 1102 & -0 & 1509 & -0 , & 1338 & & \\
\hline & & & $w^{-}{ }_{i j}$ & [ & 1746 & & 3042 & & 2756 & & 2456 & & \\
\hline
\end{tabular}

Girdi ve çıktı faktörlerinin aldıkları ağırlık değerleri ayrı ayrı değerlendirildiğinde, G2: rıhtım uzunluğu olarak tanımlanan faktörün \% 24, 83 ile en yüksek değeri aldığı, bunu G5: liman sahasında yer alan depolama alanlarının kapasitesi (\%15,96), G1: personel sayısı $(\% 15,71)$ değerleri alarak izlemişlerdir. Dördüncü önemli girdi faktörü \% 13,62 değeri alarak G4: ekipman sayısı olmaktadır. Diğer girdi faktörleri \%10,21 ila 0,078 arasında değerler alarak sıralanmaktadırlar. 
Aralık 2019, C. 14, S. 3

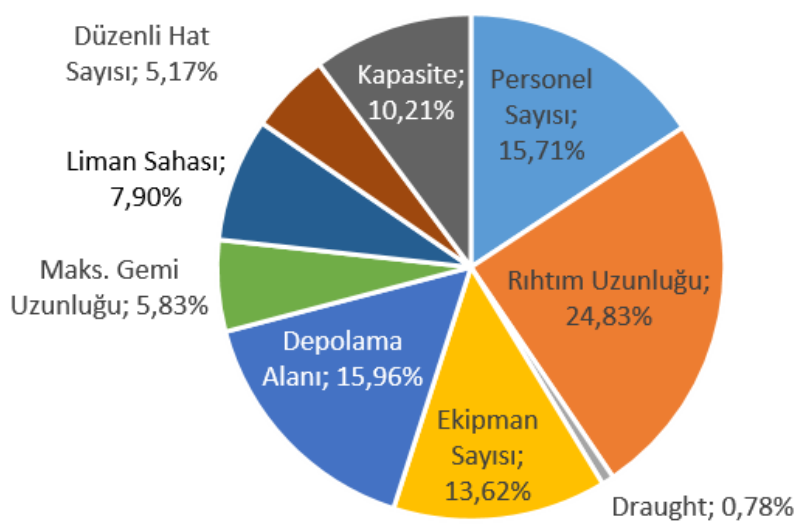

Şekil 2. Girdi Faktörleri ve Ağırlık Değerleri

Çıktı faktörlerine bakıldığında, Ç2: limanların yıllık olarak elde ettiği gelirler \%30,42 değeri ile en yüksek değere ulaşan çıktı faktörü olurken, bunu \%27,56 ile Ç3: TEU cinsinden yıllık olarak elleçlenen konteyner değeri, \%24,56 ile Ç4: yıllık elleçlenen konteyner sayısı ve \%17,46 ile yıllık hizmet alan gemi sayısı faktörleri izlemektedir.

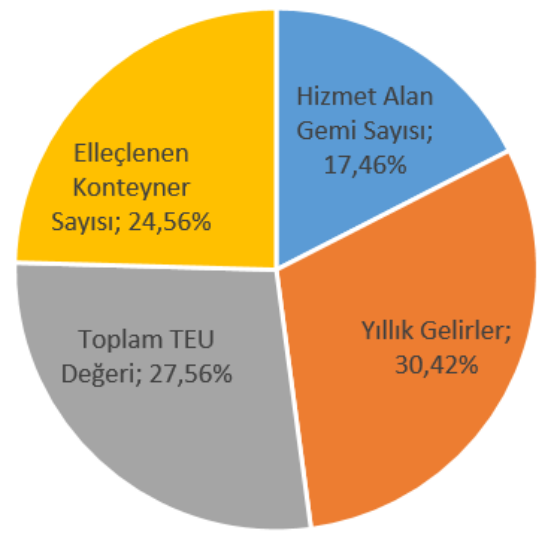

Şekil 3. Çıktı Faktörleri ve Ağırlık Değerleri

Adım-5 Girdi ve Çıktı Faktörlerinin Normalizasyonu: Bu adımda girdi ve çıktı faktörleri entropi yönteminde gerçekleştirilen normalizasyon işleminden farklı bir biçimde normalize edilmişlerdir. Eşitlik $9 a$ ve $9 \mathrm{~b}$ de gösterildiği gibi bütün girdi ve çıktı faktörleri için matris sütunlarının her birisinin karekök değerleri hesaplanmış, ardından bütün matris elemanları kendi sütununun karekök toplamına bölünerek normalize edilmiştir. İşlemin ardından normalize matrisleri göstermek üzere matris $S$ ve matris $\mathrm{R}$ oluşturulmuştur.

Öncelikle başlangıçta oluşturulan matris $X$ ve matris $Y^{\prime}$ nin her bir sütununda yer alan elemanların karekök değerleri hesaplanmıştır. 
Eskişehir Osmangazi Üniversitesi iiBF Dergisi

\begin{tabular}{|c|c|c|c|c|c|c|c|c|c|c|}
\hline \multirow{2}{*}{\multicolumn{3}{|c|}{ ГC }} & $G 2$ & \multicolumn{2}{|c|}{ G4 } & \multicolumn{2}{|c|}{ G6 } & $G 8$ & \multicolumn{2}{|c|}{$G 9$} \\
\hline & & & 540 & 8,5 & 8 & 25.000 & 540 & 260.130 & 10 & 700.000 \\
\hline & $P 2$ & 1.623 & 5.775 & 11,5 & 51 & 62.630 & 500 & 443.997 & 8 & 220.000 \\
\hline & P3 & 1.300 & 365 & 11 & 10 & 31.350 & 280 & 442.410 & 7 & 200.000 \\
\hline & $P 4$ & 3.500 & 10.200 & 13 & 55 & 202.000 & 330 & 1.410 .000 & 11 & 523.881 \\
\hline$x-$ & $P 5$ & 1.200 & 1.400 & 14,5 & 35 & 27.000 & 200 & 575.000 & 4 & 1.150 .000 \\
\hline & P6 & 766 & 1.756 & 10,5 & 7 & 50.000 & 152 & 445.000 & 12 & 250.000 \\
\hline & P7 & 205 & 2.145 & 12 & 10 & 13.000 & 152 & 240.000 & 2 & 350.000 \\
\hline & $P 8$ & 2.861 & 562 & 13 & 18 & 62.200 & 282 & 872.000 & 5 & 740.000 \\
\hline & $P 9$ & -1.200 & 2.900 & 16 & 20 & 69.000 & 150 & 512.300 & 8 & ] 185.000 \\
\hline & & 8016,8 & 12497,4 & 37,2 & 8,8 & 241582,7 & 957,7 & 2014376,5 & 24,2 & 1715277 \\
\hline
\end{tabular}

\begin{tabular}{|c|c|c|c|c|c|}
\hline & & Ç1 & Ç2 & Ç3 & Ç4 \\
\hline & $P 1$ & 13.36 & $29.958 .200,00$ & 670.536 & 413. 253 \\
\hline & $P 2$ & 7.865 & 37.513.996, 62 & 134.000 & 121.712 \\
\hline & P3 & 6.542 & $20.850 .000,00$ & 65.593 & 40.425 \\
\hline & $P 4$ & 4.607 & $4.380 .236,93$ & 245.522 & 223.007 \\
\hline & $P 5$ & 7000 & $15.930 .890,53$ & 123.078 & 75.853 \\
\hline & $P 6$ & 2.984 & $3.233 .632,15$ & 65.928 & 59.882 \\
\hline & P7 & 789 & $5.249 .253,85$ & 11.419 & 7.038 \\
\hline & $P 8$ & 1887 & 16.259.742, 50 & 224.070 & 203.522 \\
\hline & P9l & 1.300 & $5.953 .197,73$ & 82.039 & 50.561 \\
\hline & & 8.802 & 54.886. 209, 02 & 739.801 & 538.81 \\
\hline
\end{tabular}

Girdi ve çıktı faktörlerine ilişkin matrislerin her bir elamanı eşitlik 9a ve 9b kullanılarak, kendi sütunu için hesaplanmış karekök değerine bölünerek normalizasyon işlemi gerçekleştirilmiş ve normalize matrisler oluşturulmuştur.

\begin{tabular}{|c|c|c|c|c|c|c|c|c|c|}
\hline & $G 1$ & $G 2$ & G3 & G4 & G5 & $G$ & $G^{\prime}$ & G8 & G9 \\
\hline$P 1$ & {$[0,7484$} & 0,0432 & 0,2285 & 0,0901 &, 1035 & 0,5639 & 0,1291 & 0,4127 & 0,4081 \\
\hline$P 2$ & 0,2025 & 0,4621 & 0,3091 & 0,5742 & 0,2592 & 0,5221 & 0,2204 & 0,3302 & 0,1283 \\
\hline P3 & 0,1622 & 0,0292 & 0,2957 & 0,1126 & 0,1298 & 0,2924 & 0,2196 & 0,2889 & 0,1166 \\
\hline$P 4$ & 0,4366 & 0,8162 & 0,3494 & 0,6 & 0,8362 & 0,3446 & 000 & 540 & 054 \\
\hline$P 5$ & 0,1497 & $\mathbf{0}, 1$ & 0,3898 & 0,3 & $\mathbf{0}$ & 0,2 & $\mathbf{0}$, & 51 & 04 \\
\hline P6 & 0,0955 & 0,1405 & 0,2822 & 0,0788 & 0,2070 & 0,1 & $\mathbf{0}$ & $\mathbf{0}$, & 0,1457 \\
\hline P7 & 0,0256 & 0,1716 & 0,3226 & 0,1126 & 0,0538 & 0,1587 & 0,1191 & 0,0825 & 0,2040 \\
\hline$P 8$ & 0,3569 & 0,0450 & 0,3494 & 0,2027 & 0,2575 & 0,2945 & 0,4329 & 0,2064 & 0,4314 \\
\hline & , 1497 & 0,2320 & 0,4301 & 0,2252 & 0,2856 & 0,1566 & 0,2543 & 0,3302 & 0,1079 \\
\hline
\end{tabular}

\begin{tabular}{|c|c|c|c|c|}
\hline \multirow{2}{*}{\multicolumn{2}{|c|}{$P 1\left[\begin{array}{c}\text { Ç1 } \\
\mathbf{0}, \mathbf{7 1 0 8}\end{array}\right.$}} & Ç2 & Ç3 & Ç4 \\
\hline & & 0,5458 & 0,9064 & 0,7670 \\
\hline$P 2$ & 0,4183 & 0,6835 & 0,1811 & 0,2259 \\
\hline$P 3$ & 0,3480 & 0,3799 & 0,0887 & 0,0750 \\
\hline$P 4$ & 0,2450 & 0,0798 & 0,3319 & 0,4139 \\
\hline$=P 5$ & 0,3723 & 0,2903 & 0,1664 & 0,1408 \\
\hline P6 & 0,1587 & 0,0589 & 0,0891 & 0,1111 \\
\hline P7 & 0,0420 & 0,0956 & 0,0154 & 0,0131 \\
\hline$P 8$ & 0,1004 & 0,2962 & 0,3029 & 0,3777 \\
\hline$P$ & $-0,0691$ & 0,1085 & 0,1109 & 0,0938 \\
\hline
\end{tabular}

Adım-6 Faktörlerin Mesafe Ölçütlerinin Belirlenmesi: Girdi faktörlerinin mesafe ölçütlerinin belirlenmesi için eşitlik 11a ve 11b kullanılmış, bütün girdi faktörlerine ilişkin matris ele- 
manları için mesafe ölçütleri hesaplanarak, tüm matris elemanlarının mesafe ölçütlerini gösteren matris I oluşturulmuştur. Aynı işlem eşitlik 12a ve 12b kullanılarak çıktı faktörlerine ilişkin matris elemanları için yapılmış ve matris $\mathrm{O}$ oluşturulmuştur.

I

$$
\begin{array}{lllllllll}
G 1 & G 2 & G 3 & G 4 & G 5 & G 6 & G 7 & G 8 & G 9
\end{array}
$$

\begin{tabular}{|c|c|c|c|c|c|c|c|c|c|}
\hline$P 1$ & {$[1,7229$} & 1,0140 & 1,0000 & 1, 0113 & 7 & 72 & 1,0 & 2 & \\
\hline$P 2$ & 1,1769 & 1,4329 & 1,0806 & 1,4954 & 1,2054 & 1,3655 & $\mathbf{1}$, & 1,2476 & \\
\hline$P 3$ & 1366 & 00 & 0672 & 0338 & 60 & 57 & 05 & 64 & \\
\hline$P 4$ & 10 & $1, ?$ & 10 & & & & & & \\
\hline$P 5$ & 1,1241 & 1,0 & 1,1 & 1,3 & & 22 & & 1, & 526 \\
\hline P6 & 1,0700 & 1,1 & 1,0 & 1,0000 & 1,1 & 21 & 1 & 1,4127 & 379 \\
\hline P7 & 0000 & 1,1 & 0941 & 1,0338 & 1,0 & 21 & 1, & 1,0000 & 962 \\
\hline P8 &, 3313 & 1,0158 & 1,1210 & 1,1239 & 1,2037 & 1,1378 & 1, 3137 & 1,1238 & 1,3236 \\
\hline 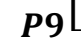 & $L_{1}, 1241$ & 1,2028 & 1,2016 & 1,1464 & 1,2318 & 1,0000 & 1,1352 & 1,2476 & 1,000 \\
\hline
\end{tabular}

\begin{tabular}{|c|c|c|c|c|}
\hline$P 1$ & $\begin{array}{c}\text { Ç1 } \\
{[\mathbf{1}, \mathbf{0 0 0 0}}\end{array}$ & $\begin{array}{c}\text { Ç2 } \\
\mathbf{0 , 8 6 2 3}\end{array}$ & $\begin{array}{c}\text { Ç3 } \\
\mathbf{1 , 0 0 0 0}\end{array}$ & $\begin{array}{c}\text { Ç. } \\
\mathbf{1}, \mathbf{0 0 0 0}\end{array}$ \\
\hline$P 2$ & 0,7075 & 1,0000 & 0,2748 & 0,4589 \\
\hline$P 3$ & 0,6371 & 0,6964 & 0,1823 & $\mathbf{0}, \mathbf{3 0 8 1}$ \\
\hline$P 4$ & 0,5342 & 0,3963 & 0,4255 & 0,6469 \\
\hline$P 5$ & 0,6615 & 0,6068 & 0,2600 & 0,3738 \\
\hline$P 6$ & 0,4479 & 0,3754 & 0,1827 & 0,3442 \\
\hline P7 & 0,3311 & 0,4122 & 0,1091 & 0,2461 \\
\hline$P 8$ & 0,3895 & 0,6128 & 0,3965 & 0,6108 \\
\hline$P 9$ & $L_{0,3583}$ & 0,4250 & 0,2045 & 0,3269 \\
\hline
\end{tabular}

Adım-7 Mesafe Ölçütlerinin Ağırlıklandırııması: Eşitlik 13a ve 13b kullanılarak, bir önceki adımda bütün faktörler için belirlenen mesafe ölçütleri entropi yöntemi kullanılarak elde edilen faktör ağırlıkları ile çarpılarak mesafe ölçütleri ağırıklandırılmış ve buna ilişkin matrisler oluşturulmuştur.

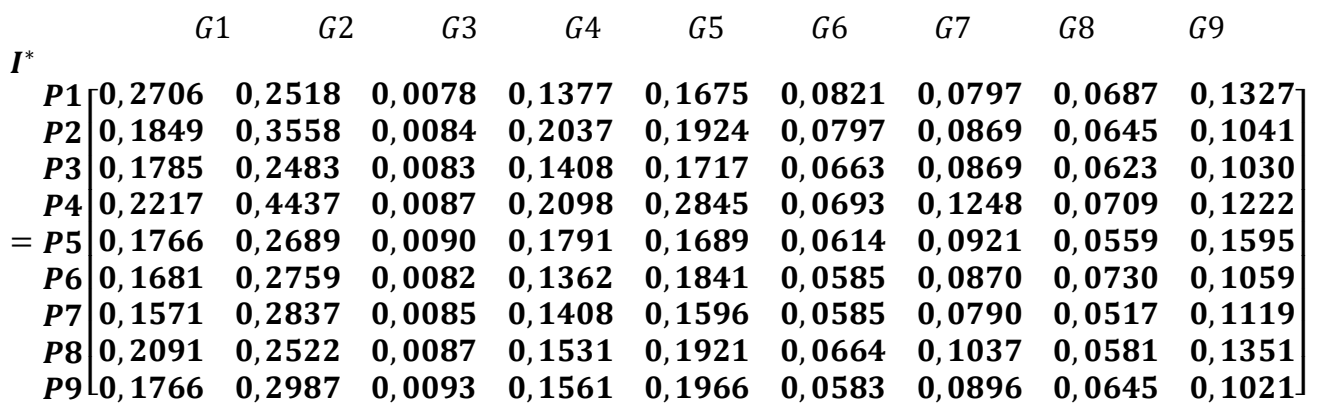




$$
\begin{aligned}
& \text { Ç1 Ç2 Ç3 Ç4 } \\
& P 1\left[\begin{array}{llll}
0,1746 & 0,2623 & 0,2756 & 0,2456
\end{array}\right] \\
& \begin{array}{l|llll}
P 2 & 0,1236 & 0,3042 & 0,0757 & 0,1127
\end{array} \\
& \begin{array}{l|llll}
P 3 & 0,1113 & 0,2118 & 0,0502 & 0,0757
\end{array} \\
& \begin{array}{l|llll}
P 4 & 0,0933 & 0,1206 & 0,1173 & 0,1589
\end{array} \\
& O^{-}=P 5 \mid \begin{array}{lllll}
0,1155 & 0,1846 & 0,0717 & 0,0918
\end{array} \\
& \begin{array}{l|llll}
P 6 & 0,0782 & 0,1142 & 0,0504 & 0,0845
\end{array} \\
& \begin{array}{l|llll}
P 7 & 0,0578 & 0,1254 & 0,0301 & 0,0604
\end{array} \\
& \begin{array}{l|lllll}
P 8 & 0,0680 & 0,1864 & 0,1093 & 0,1500
\end{array} \\
& P 9\left[\begin{array}{llll}
0,0626 & 0,1293 & 0,0564 & 0,0803
\end{array}\right]
\end{aligned}
$$

Adım-8 Verimlilik Değerlerinin Hesaplanması: Eşitlik 15 kullanılarak her bir karar noktası için verimlilik skoru hesaplanmıştır. Bunun için ağırıklandırılmış mesafe ölçütleri matrisi I'’’n her bir satır toplamı çıktı faktörleri için söz konusu olan $0^{-}$matrisinin aynı satır toplamına bölünmekte ve verimlilik değeri hesaplanmaktadır.

$\begin{array}{clcccc}\text { Kodu } & \text { Liman } & \text { Girdi } & \text { Çıtk } & \text { Verimlilik } & \text { Sira } \\ \text { P1 } & \text { Constanza } & 1,1987 & 0,9581 & 0,7993 & 1 \\ \text { P2 } & \text { Varna } & 1,2804 & 0,6162 & 0,4812 & 2 \\ \text { P3 } & \text { Burgaz } & 1,0661 & 0,4490 & 0,4211 & 4 \\ \text { P4 } & \text { Odessa } & 1,5556 & 0,4900 & 0,3150 & 6 \\ \text { P5 } & \text { Ilıcevsk } & 1,1714 & 0,4635 & 0,3957 & 5 \\ \text { P6 } & \text { Samsun } & 1,0968 & 0,3273 & 0,2984 & 7 \\ \text { P7 } & \text { Trabzon } & 1,0506 & 0,2737 & 0,2605 & 9 \\ \text { P8 } & \text { Novorossysk } & 1,1785 & 0,5137 & 0,4359 & 3 \\ \text { P9 } & \text { Poti } & 1,1518 & 0,3285 & 0,2852 & 8\end{array}$

\section{Sonuç ve Öneriler}

Seçilen hibrid model kullanılarak gerçekleştirilen analizde, değerlendirme için belirlenen girdi ve çıktı faktörlerin önem değerleri dikkate alındığında; 0,24830 puanıyla G2: konteyner limanlarının rıhtım uzunlukları en önemli faktör olarak belirlenmiştir. Bu faktörü G5: Depolama alanı $(0,15962)$ ve G1: Personel Sayısı $(0,15709)$ faktörleri izlemektedir.

Bu üç faktörden hemen sonra 0,13619 ile G4: Ekipman Sayısı faktörü gelmektedir. Diğer faktörler 0,10206 ila 0,00778 arasında değerler alarak sıralanmaktadır. Rıhtım uzunluğunun diğer faktörlere göre daha önemli olmasının nedenleri arasında rıhtım uzunluğu arttığında kullanılacak ekipman, işgücü vb. unsurların artış göstereceği, aynı zamanda yaratacağı trafiğin ciddi oranda artacak olması söylenebilir. Buna karşılık ekipman ve personel sayısı konteyner limanlarının en temel girdileri arasında yer almakta, bu faktörler artırıldığında limanın maliyetleri de doğrudan artmaktadır.

Çıktı faktörlerine göz atıldığında; konteyner limanları için en önemli faktörün 0,30419 puan ile yıllık gelir olduğu görülmektedir. Bunu 0,27559 değeri ile TEU cinsinden elleçlenen miktarı, 0,24559 puan ile elleçlenen konteyner sayısı, nihayet 0,17464 puan ile yıllık hizmet verilen gemi sayısı izlemektedir.

Karadeniz de yer alan en yüksek verimliliğe sahip konteyner limanı Constanza limanı olarak belirlenmiştir. Limanın verimlilik puanı rakiplerine göre son derece yüksektir. Bunun temel 
nedenlerinin başında limanın çıktı skorunun rakiplerine göre oldukça yüksek olması sayılabilmektedir. Buna karşılık limanın kullandığı girdi düzeyi rakiplerinden bir miktar altında kalmaktadır. Dolayısıyla Constanza limanı girdi olarak ortalamaya yakın, çıktı olarak ise rakiplerinin bir hayli üzerinde olması neticesinde en yüksek verimliliğe sahip liman olmaktadır.

Daha geniş bir perspektifte değerlendirildiğinde Constanza limanı en yüksek personel sayısına sahip olan limandır. Buna ek olarak, Rıhtım uzunluğu Burgas limanı hariç diğer tüm limanlardan daha düşük düzeydedir. Depolama alanı açısından ise Trabzon limanı dışında kalan diğer tüm limanlardan daha düşük depolama kapasitesine sahiptir. Ek olarak liman vinçleri gibi ekipmanlar açısından sadece Samsun limanı hariç en az sayıda ekipmana sahip liman olarak görülmektedir. Buna karşılık çıktı faktörlerine ilişkin değerleri gözden geçirildiğinde bütün çıktı faktörleri açısından en yüksek değerleri aldığı görülebilmektedir.

íkinci en verimli liman olan Varna limanına bakıldığında girdi kullanımının Constanza limanına göre daha yüksek olmasına karşılık, çıktı düzeyi söz konusu limanın gerisinde kalmaktadır. Odesa limanı hariç diğer tüm limanlar arasında en yüksek girdi kullanan liman konumunda iken, çıktı faktörleri açısından Constanza limanı dışında diğer tüm limanlar arasında en yüksek değere sahip liman olarak kaydedilmiştir.

Odesa limanı diğer tüm limanlara kıyasla en yüksek girdi kullanan konteyner limanı olma konumundayken, buna karşılık elde ettiği çıktı değerleri rakiplerine kıyasla düşük kalmakta, bu nedenle dokuz konteyner limanı arasında verimlilik ve performans açısından kendisine altıncılıkta yer bulabilmektedir.

Performans ve verimlilik açısından en kötü pozisyonda olan limanlara bakıldığında son üç sırada yer alan Samsun, Poti ve Trabzon limanları girdi kullanımı açısından rakiplerine yakın bir düzeye sahipken, elde ettikleri çıktılara bakıldığında rakiplerine kıyasla son derece düşük değerler aldıkları görülmektedir. Dolayısıyla bu limanların girdi kullanımı ile ilgili problemleri söz konusu değilken, elde edecekleri çıktıları artırabilecek önlemler geliştirmeleri öncelikli stratejileri olabilir. Odesa limanı dışarıda bırakılırsa bu üç limanın elde ettikleri yıllık gelir 3 ila 6 milyon Euro arasında olup, en yüksek performansa sahip rakiplerinin elde ettiği gelire oranlandığında elde ettikleri gelir en yüksek yıllık gelire sahip limanın \%8,61'ine denk gelmektedir. Kendilerine en yakın rakiplerinin ise elde ettiği yıllık gelirin \%29,30 düzeyinde gelir elde etmektedirler.

Samsun limanı dikkate alındığına hizmet verilen gemi sayısının 2984 olarak Trabzon limanının üzerinde bir değer aldığı, TEU cinsinden elleçlenen konteyner miktarı Trabzon limanının elleçlediği TEU değerinin yaklaşık altı katına ulaşırken, elde ettiği gelirler 3,23 milyon Euro olarak Trabzon limanının altında kalmıştır. Bunun temel nedenlerinin başında samsun limanının konteyner taşımacılığına ek olarak Ro-Ro operasyonlarına odaklanması ve rekabet edebilirlik düzeyini artırabilmek için konteyner için verdiği hizmetin bedelini bir miktar düşük tutmak istemesi gelebilmektedir. 


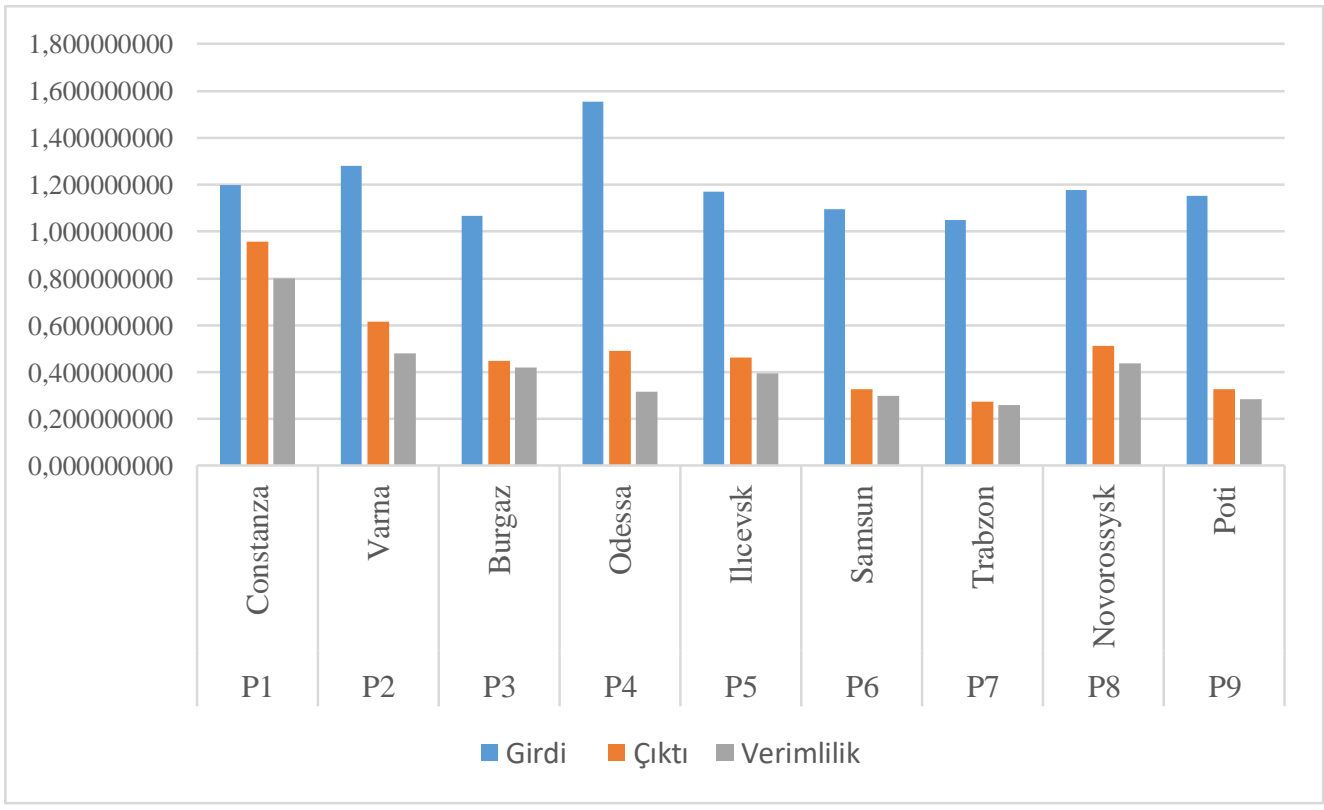

Şekil 6. Karadeniz konteyner limanlarının girdi, çıktı ve verimlilik skorları

Sonuç olarak bakıldığında her iki limanın girdi kullanımının son derece iyi bir durumda olduğu görülebilmektedir. Bu nedenle limanların rekabet edebilirlik açısından girdi kullanımını artırmaları gerekli değilken, elde ettikleri çıktılar rakiplerine kıyasla son derece düşüktür. Bu nedenle bu limanların çıktı düzeyini artıracak önlemlere odaklanması verimlilik ve etkinliklerini artırmak için son derece yerinde kararlar olabilir. Bu perspektifte bağlantılı oldukları liman ve hat sayılarının artırııması, bunun için çeşitli düzeyde işbirliği ortamının oluşturulması, transit taşımalarda operasyonların mümkün olduğunca hızlandırılması bu limanlara gerçekleşen konteyner akışını bir miktar daha artırabilecektir.

Buna bağlı olarak Trabzon limanında depolama kapasitesi, samsun limanında ise elleçleme ekipmanı sayısı bir miktar artırılabilir. Bu sayede limanlarda gerçekleşen lojistik akış hızı önemli ölçüde artırılabilir. Ek olarak yüksek katma değerli hizmetler üretilerek, birim hizmetin, dolayısıyla kullanıcıların ödeyecekleri hizmet bedeli bir miktar artırılabilir. Nihai olarak değerlendirildiğinde Karadeniz bölgesinde yer alan limanlarımızın giderek artan rekabete uygun bir biçimde yeniden planlanmaları ve yapılandırılmaları gerekmektedir. 


\section{Kaynaklar}

Anderson, Christopher; Park, Yong-An; Chang, Young-Tae; Yang, Chang-Ho; Lee, Tae-Woo; Luo, Meifeng (2008). “A Game-Theoretic Analysis of Competition Among Container Port Hubs: The Case of Busan and Shanghai", Maritime Policy \& Management, Vol. 35, No. 1: 5-26.

Barros, Carlos, Pestana (2003). "The Measurement of Efficiency of Portuguese Seaport Authorities with DEA", International Journal of Transport Economics, Vol. 30 No.3: 335-354.

Barros, Carlos, Pestana; Athanassiou M. (2004). "Efficiency in European Seaports with DEA. Evidence from Greece and Portugal”, Maritime Economics \& Logistics, Vol. 6, No. 2: 122-140.

Bichou, Khalid; Gray, Richard (2004). "A Logistics and Supply Chain Management Approach to Port Performance Measurement", Maritime Policy and Management, Vol. 31, No.1: 47-67.

Çanakçıoğlu, Mustafa (2019). "Borsa İstanbul'da İşlem Gören Çimento Firmalarının Entropi-EATWıOS Bütünleşik Yaklaşımı ile Finansal Performanslarının Değerlendirilmesi”, Yaşar Üniversitesi Dersisi, Vol 14, No. 56: 407-421.

Clark, Ximena; Dollar, David; Micco, (2004). "Alejandro Port Efficiency, Maritime Transport Costs, And Bilateral Trade", Journal of Development Economics, Vol. 75, No. 2: 417-450.

Cullinane, Kevin; Song, Dong-Wook (2003). "A Stochastic Frontier Model of the Productive Efficiency of Korean Container Terminals", Applied Economics, Vol. 35, No. 3: 251-267.

Cullinane, Kevin; Song, Dong-Wook; Gray, Richard (2002). "A Stochastic Frontier Model of the Efficiency of Major Container Terminals in Asia: Assessing The Influence of Administrative and Ownership Structures", Transportation Research Part A: Policy and Practice Volume 36, No. 8: 743-762.

Cullinane, Kevin; Song, Dong-Wook; Wang, Teng-Fei (2005). "The Application of Mathematical Programming Approaches to Estimating Container Port Production Efficiency", Journal of Productivity Analysis, Vol. 24, No.1: 73-92.

Cullinane, Kevin; Song, Dong-Wook; Wang, Teng-Fei (2005). "The Application of Mathematical Programming Approaches to Estimating Container Port Production Efficiency", Journal of Productivity Analysis Vol. 24, No. 1: $73-92$.

Cullinane, Kevin; Wang, Teng-Fei (2006). "The Efficiency of European Container Ports: A Cross-Sectional Data Envelopment Analysis", International Journal of Logistics: Research and Applications, Vol. 9, No. 1: 19-31.

Cullinane, Kevin; Wang, Teng-Fei (2010). "The Efficiency Analysis of Container Port Production Using DEA Panel Data Approaches", OR Spectrum, Vol. 32 No.3: 717-738.

Cullinane, Kevin; Wang, Teng-Fei; Song, Dong-Wook; Ji, Ping (2006). "The Technical Efficiency of Container Ports: Comparing Data Envelopment Analysis and Stochastic Frontier Analysis", Transportation Research Part A: Policy and Practice, Vol. 40, No.4: 354-374.

Jasmine, Siu; Lee, Lam; Wei, Yim-Yap (2011). "Dynamics of Liner Shipping Network and Port Connectivity in Supply Chain Systems: Analysis on East Asia", Journal of Transport Geography, Vol. 19, No. 6: 1272-1281.

Jim, Yen-Chun Wua; Mark, Goh (2010). "Container Port Efficiency in Emerging and More Advanced Markets", Transportation Research Part E: Logistics and Transportation Review, Vol. 46, No. 6: 1030-1042.

Langen, Peter; Visser, Evert-Jan (2005). "Collective Action Regimes in Seaport Clusters: The Case of the Lower Mississippi Port Cluster", Journal of Transport Geography, Vol. 13, No. 2: 173-186.

Lirn, Taih-Cherng; Thanopoulou, Helen; Beynon, Malcolm; Beresford, Anthony (2004). "An Application of AHP on Transshipment Port Selection: A Global Perspective”, Maritime Economics \& Logistics, March, Vol. 6, No. 1: 70-91,

Malchow, Matthew; Kanafani, Adib (2004). “Disaggregate Analysis of Port Selection”, Transportation Research Part E, Vol. 40, No. 4: 317-338.

Notteboom, Theo (2010). "Concentration and The Formation of Multi-Port Gateway Regions in The European Container Port System: An Update", Journal of Transport Geography, Vol. 18, No. 4: 567-583.

Notteboom, Theo; Coeck, Chris; Broeck, Julien Van Den (2007). "Measuring and Explaining the Relative Efficiency of Container Terminals by Means of Bayesian Stochastic Frontier Models", International Journal of Maritime Economics, Vol. 2: 83-106.

Notteboom, Theo; Rodrigue, Jean-Paul (2005). "Port Regionalization: Towards A New Phase in Port Development", Maritime Policy \& Management, Vol. 32, No.3: 297-313.

Panayides, Photis M.; Maxoulis, Christos; Wang, Teng-Fei; Ng K.Y, Adolf (2009). “A Critical Analysis of DEA Applications to Seaport Economic Efficiency Measurement", Transport Reviews, Vol. 29, No. 2: 183-206. 


\section{Eskişehir Osmangazi Üniversitesi iißBF Dergisi}

Park, Ro-kyung; De Prabir (2015). An Alternative Approach to Efficiency Measurement of Seaports. In: Haralambides H.E. (eds) Port Management. Palgrave Readers in Economics. Palgrave Macmillan, London.

Parola, Francesco; Sciomachen, Anna (2005). "Intermodal Container Flows in A Port System Network: Analysis of Possible Growths Via Simulation Models", International Journal of Production Economics, Vol. 97, No. 1: 75-88

Roll, Yaakov; Hayuth, Yehuda (1993) "Port Performance Comparison Applying Data Envelopment Analysis (DEA)", Maritime Policy \& Management, Vol. 20, No. 2: 153-161.

Sanchez, Ricardo; Hoffmann, Jan; Micco, Alejandro; Pizzolitto, Georgina; Sgut, Martín; Wilmsmeir, Gordon (2003). "Port Efficiency and International Trade: Port Efficiency as A Determinant of Maritime Transport Costs", Maritime Economics and Logistics, Vol. 5 No. 2: 199-218

Song, Dong-Wook; Yeo, Ki-Tae (2004). "A Competitive Analysis of Chinese Container Ports Using the Analytic Hierarchy Process", Maritime Economics \& Logistics, Vol. 6, No. 1: 34-52.

Stahlbock, Robert; Voß, Stefan (2008). “Operations Research at Container Terminals: A Literature Update”. OR Spectrum, Vol. 30, No. 1: 1-52.

Tongzon, Jose (2001). "Efficiency Measurement of Selected Australian and Other International Ports Using Data Envelopment Analysis", Transportation Research Part A: Policy and Practice, Vol. 35, No. 2: 113-128.

Tongzon, Jose; Heng, Wu (2005). "Port Privatization, Efficiency and Competitiveness: Some Empirical Evidence from Container Ports (Terminals)", Transportation Research Part A: Policy and Practice, Vol. 39, No.5: 405-424.

Trujillo, Lourdes; Tovar, Beatriz (2007). "The European Port Industry: An Analysis of its Economic Efficiency", Maritime Economics \& Logistics, June, Vol. 9, No. 2: 148-171.

Valentine, Vincent Francis; Gray, Robert. (2001). The Measurement of Port Efficiency Using Data Envelopment Analysis, Proceedings of the Ninth World Conference on Transport Research, Seoul, 22-27 July.

Wang, Teng-Fei; Song, Dong-Wook; Cullinane, Kevin (2003). "Container Port Productıon Efficiency: A Comparative Study of DEA and FDH Approaches", Journal of the Eastern Asia Society for Transportation Studies, Vol.5: 698-713.

Wang, Yuhong; Cullinane, Kevin (2014). Traffic Consolidation in East Asian Container Ports: A Network Flow Analysis, Transport. Res. Part A: Policy Practice, Vol. 61: 152-163.

Wiegmans, Bart; Van Der Hoest, Anthony; Notteboom, Theo (2008). "Port and Terminal Selection by Deep-Sea Container Operators", Maritime Policy and Management, Vol. 35 No.6: 517-534.

Yeo, Gi-Tae; Roe, Michael; Dinwoodie, John (2008). "Evaluation The Competitiveness of Container Ports in Korea and China", Transportation Research, Vol. 42 No. A: 910-921. 